\title{
Article \\ Phytochemical Diversity and Antioxidant Potential of Natural Populations of Nelumbo nucifera Gaertn. throughout the Floristic Regions in Thailand
}

\author{
Duangjai Tungmunnithum ${ }^{1,2,3, * \mathbb{D}}$, Samantha Drouet ${ }^{2}$ and Christophe Hano ${ }^{2,3, * \mathbb{D}}$ \\ 1 Department of Pharmaceutical Botany, Faculty of Pharmacy, Mahidol University, Bangkok 10400, Thailand \\ 2 Laboratoire de Biologie des Ligneux et des Grandes Cultures, INRAE USC1328, Campus Eure et Loir, \\ Orleans University, 28000 Chartres, France; samantha.drouet@univ-orleans.fr \\ 3 Le Studium Institute for Advanced Studies, 1 Rue Dupanloup, 45000 Orleans, France \\ * Correspondence: duangjai.tun@mahidol.ac.th (D.T.); hano@univ-orleans.fr (C.H.)
}

\section{check for}

updates

Citation: Tungmunnithum, D.;

Drouet, S.; Hano, C. Phytochemical

Diversity and Antioxidant Potential of Natural Populations of Nelumbo nucifera Gaertn. throughout the Floristic Regions in Thailand. Molecules 2022, 27, 681. https:// doi.org/10.3390/molecules27030681

Academic Editors: Gianluca Paventi, Giuseppe Rotundo and Giacinto S. Germinara

Received: 31 December 2021

Accepted: 18 January 2022

Published: 20 January 2022

Publisher's Note: MDPI stays neutral with regard to jurisdictional claims in published maps and institutional affiliations.

Copyright: (c) 2022 by the authors. Licensee MDPI, Basel, Switzerland. This article is an open access article distributed under the terms and conditions of the Creative Commons Attribution (CC BY) license (https:// creativecommons.org/licenses/by/ $4.0 /)$.

\begin{abstract}
Asian lotus has long been consumed as a food and herbal drug that provides several health benefits. The number of studies on its biological activity is significant, but research at the population level to investigate the variation in phytochemicals and biological activity of each population which is useful for a more efficient phytopharmaceutical application strategy remains needed. This present study provided the frontier results to fill-in this necessary gap to investigating the phytopharmaceutical potential of perianth and stamen, which represent an important part for Asian traditional medicines, from 18 natural populations throughout Thailand by (1) determining their phytochemical profiles, such as total contents of phenolic, flavonoid, and anthocyanin, and (2) determining the antioxidant activity of these natural populations using various antioxidant assays to examine different mechanisms. The result showed that Central is the most abundant floristic region. The stamen was higher in total phenolic and flavonoid contents, whereas perianth was higher in monomeric anthocyanin content. This study provided the first description of the significant correlation between phytochemical contents in perianth compared with stamen extracts, and indicated that flavonoids are the main phytochemical class. This analysis indicated that the stamen is a richer source of flavonoids than perianth, and provided the first report to quantify different flavonoids accumulated in stamen and perianth extracts under their native glycosidic forms at the population level. Various antioxidant assays revealed that major flavonoids from $N$. nucifera prefer the hydrogen atom transfer mechanism when quenching free radicals. The significant correlations between various phytochemical classes and the different antioxidant tests were noted by Pearson correlation coefficients and emphasized that the antioxidant capability of an extract is generally the result of complex phytochemical combinations as opposed to a single molecule. These current findings offer the alternative starting materials to assess the phytochemical diversity and antioxidant potential of N. nucifera for phytopharmaceutical sectors.
\end{abstract}

Keywords: phytochemical profiles; antioxidant potential; Nelumbo nucifera; sacred lotus; Nelumbonaceae; population level; floristic regions

\section{Introduction}

Nelumbo nucifera Gaertn. is an aquatic perennial plant species belonging to the Nelumbonaceae family [1-5]. This plant is also commonly known by its common names, e.g., lotus, sacred lotus, Asian lotus, or Indian lotus [1-3,5,6]. N. nucifera is mainly distributed in tropical and subtropical regions of Asia, such as Thailand, China, Napal, India, and other Asian nations. This lotus species was also introduced to some countries in the European Union, such as Romania and Hungary [7].

N. nucifera is well-recognized for its beautiful flowers, especially the color, size. and morphology of its perianth (petal). This sacred lotus has also been considered as a spiritual symbol for Buddhists and Hindus since the ancient periods. Furthermore, N. nucifera also 
offers many health benefits to mankind. For example, its perianth and rhizomes are used as vegetable ingredients for various type of cuisines. Additionally, its seeds can be consumed as fresh fruit. Besides, many parts of its flower are also employed in important recipes for traditional medicines or herbal drugs, especially in Thai traditional medicines and Chinese traditional medicines [5,6,8-11]. The perianth and stamen are also used to prepare herbal teas for relaxation and healthy benefits $[5,6,9]$.

During the last two decades, the number of research studies to evaluate the potential biological activities of $N$. nucifera have considerably increased [8-17]. Several parts of this lotus species have been investigated, i.e., the antioxidant effect from stamen methanolic extract [12], the seed hydroalcoholic extract [18], epicarp extract [15], embryo extract [16,19], as well as leaf extract [8,11]. In addition, the anti-obesity activity [20], anti-inflammatory activity [21,22], enhancement of sleeping quantity and quality [23], potential to improve muscle wasting [24], as well as UV-protection and anticancer potential [25] of N. nucifera leaf extract were also reported by previous research works. The therapeutic effect of $N$. nucifera methanolic extract on pathological cardiomyocyte hypertrophy was also evaluated [26]. The anti-Alzheimer's disease potential of the aqueous extract of the mixture from leaf, flower (petal and stamen), petiole, peduncle, and seed embryo of N. nucifera was also studied [27]. According to the previously published works, it is obvious that there is no research study that examined the biological activity or phytochemical profiles of $N$. nucifera at the population level. Nevertheless, the great variation among several populations in each plant species, which may possibly lead to the variation in phytochemical profiles and effect on biological activities, should be taken into account $[28,29]$. Moreover, Thailand is one of the important hot spots of species biodiversity, including N. nucifera plants.

The present study aimed to study the variation in phenolic compounds (phenolics, flavonoids, and anthocyanins) and antioxidant properties of stamen and perianth extracts of $18 \mathrm{~N}$. nucifera populations from different geographical regions in Thailand. The goal of this study is to complete this knowledge by determining the total phenolic, flavonoid (including HPLC determination of the main flavonoids), and anthocyanin contents as well as antioxidant activity using several in vitro assays based on different mechanisms, with 18 natural populations originating from all Thai floristic regions.

\section{Results and Discussion}

\subsection{Plant Populations and Botanical Description}

According to the field study and the intense search for living plant specimens of $N$. nucifera in the fields, 18 populations of this sacred lotus species were collected from different localities (provinces) covering all seven floristic regions in Thailand, as shown in the Table 1.

The distribution map of the collected 18 N. nucifera populations throughout Thailand is provided in Figure 1. According to the distribution of these 18 populations of this lotus species (Table 1 and Figures 1 and 2), the most abundant floristic region in Thailand is the Central floristic region, where five populations of $N$. nucifera were found. The second most abundant floristic regions belong to Northern and North-Eastern floristic regions, where 4 populations of $N$. nucifera were found. The botanical description of $N$. nucifera (Nelumbonaceae family) used in this study is provide in the paragraph below.

Aquatic perennial, rhizomatous. Petiole 1-2.3 m, terete, glabrous or papillae hard and scattered. Leaf orbicular, blue-green, $28.5-90.5 \mathrm{~cm}$ in diam., glabrous, glaucous, waterrepellent, margin entire. Flowers $9.5-24.5 \mathrm{~cm}$ in diam. Peduncles longer than petioles, glabrous or sparsely spinulate. Perianth caducous, oblong, oblong-elliptic or obovate, pink or white, $4.5-10.5 \times 2.7-5.5 \mathrm{~cm}$. Stamens longer than receptacle, filament slender; anther linear, 1-2.5 mm; connective appendage. Receptacle accrescent, turbinate, $4.5-9.5 \mathrm{~cm}$ in diam. Ovary Superior. Fruit oblong or ovoid, 1.3-2.5 × 6.5-15 cm, glabrous, pericarp thick, hardened. 


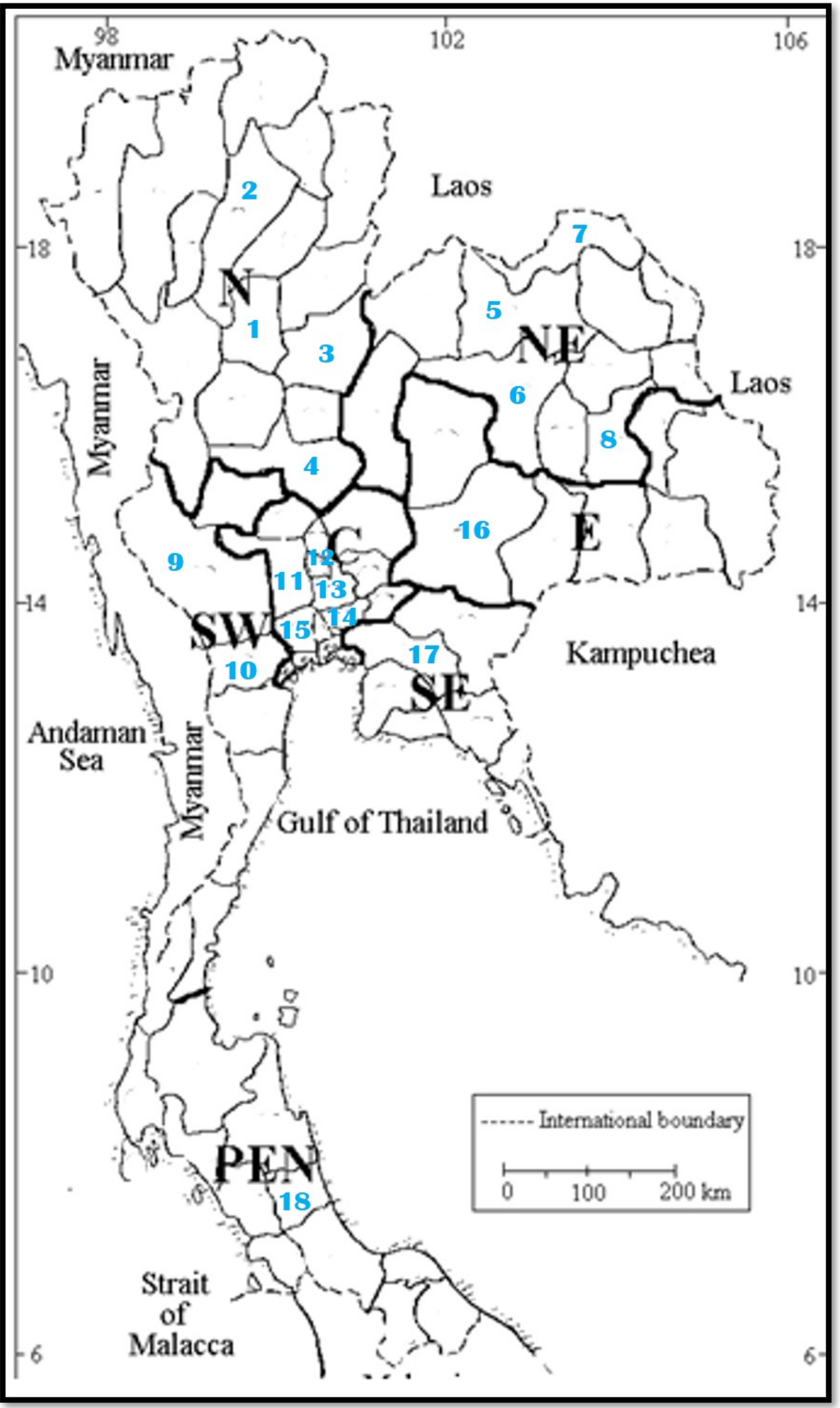

Figure 1. The distribution map of $N$. nucifera 18 populations collected from the natural habitat cover the floristic region in Thailand. The number 1-18 in the map indicates the population number. 

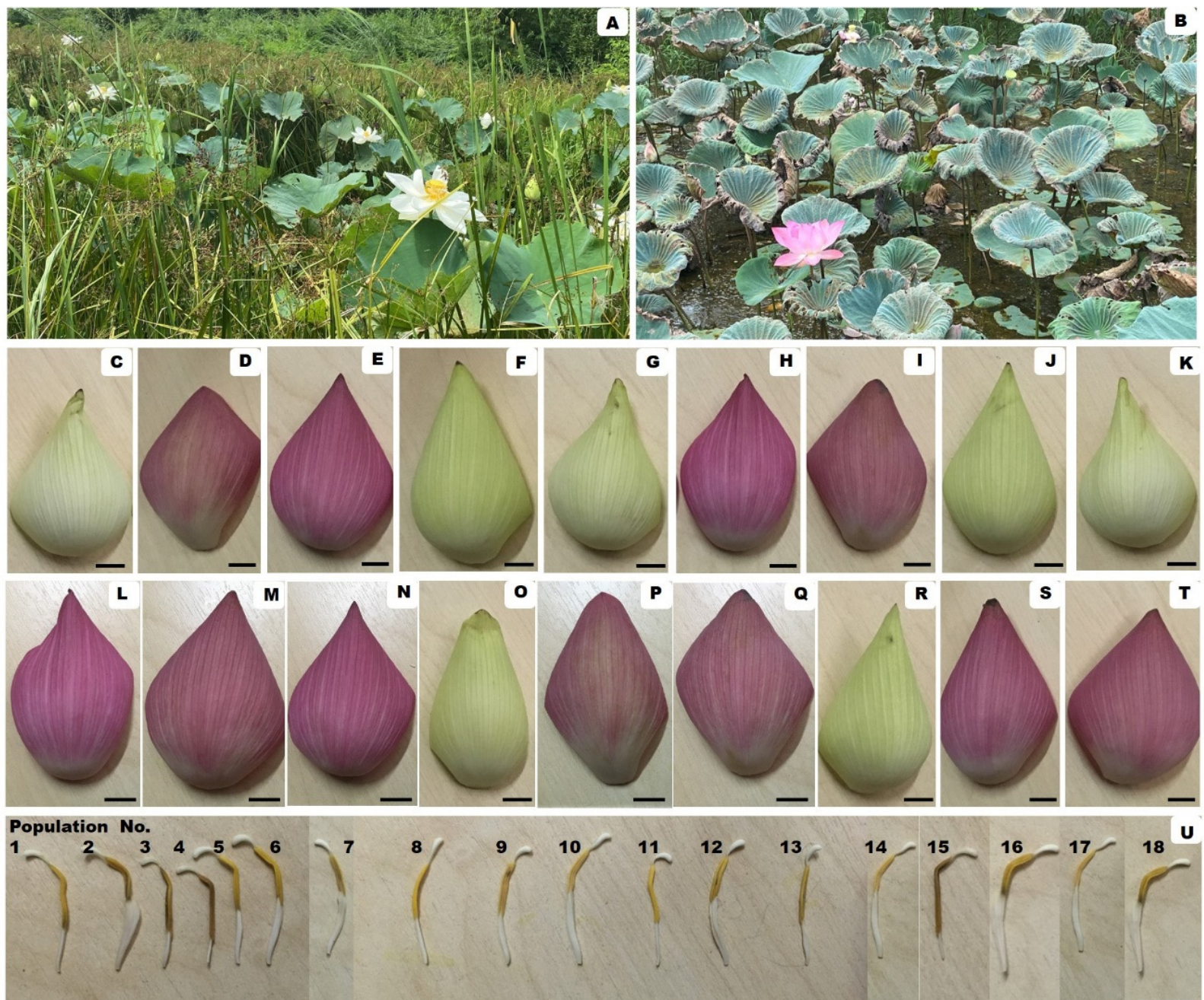

Figure 2. N. nucifera: (A,B). Natural habitats; (C-T). Perianth of Population No. 1-18, respectively; (U). Stamen of Population No. 1-18, respectively; Bar scale $=1 \mathrm{~cm}$. Photo are taken in Thailand by Duangjai Tungmunnithum.

Table 1. The collected 18 populations of N. nucifera throughout Thailand.

\begin{tabular}{|c|c|c|c|c|}
\hline Floristic Regions & $\begin{array}{c}\text { Population } \\
\text { No. }\end{array}$ & $\begin{array}{c}\text { Collected } \\
\text { Locations/Provinces }\end{array}$ & $\begin{array}{l}\text { Collected } \\
\text { Months }\end{array}$ & $\begin{array}{c}\text { Collected } \\
\text { Season }\end{array}$ \\
\hline \multirow{4}{*}{ Northern (N) } & 1 & Sukhothai & April & Summer \\
\hline & 2 & Lampang & May & Summer \\
\hline & 3 & Phitsanulok & August & Rainy \\
\hline & 4 & Nakhon Sawan & September & Rainy \\
\hline \multirow{4}{*}{ North-Eastern (NE) } & 5 & Udon Thani & November & Winter \\
\hline & 6 & Khon Kaen & April & Summer \\
\hline & 7 & Nong Khai & September & Rainy \\
\hline & 8 & Roi Et & November & Winter \\
\hline \multirow{2}{*}{ South-Western (SW) } & 9 & Kanchanaburi & April & Summer \\
\hline & 10 & Ratchaburi & September & Rainy \\
\hline \multirow{2}{*}{ Central (E) } & 11 & Suphan Buri & November & Winter \\
\hline & 12 & Angthong & Decemember & Winter \\
\hline \multirow{4}{*}{ Eastern (E) } & 13 & Phra NakhonSi Ayuthaya & May & Summer \\
\hline & 14 & Pathum Thani & October & Rainy \\
\hline & 15 & Nakhon Pathom & April & Summer \\
\hline & 16 & Nakhon Ratchasima & September & Rainy \\
\hline South-Eastern (SE) & 17 & Chachoengsao & April & Summer \\
\hline Peninsular (PEN) & 18 & Phatthalung & September & Rainy \\
\hline
\end{tabular}


Specimens examined: Stamens and perianths of N. nucifera populations \#1-18.

\subsection{Phytochemical Characterization}

The total phenolic and flavonoid contents, as well as monomeric anthocyanin contents (TPC, TFC, and MAC, respectively) found in stamen (S) and perianth (P) extracts of $N$. nucifera populations from across Thailand's floristic regions ranged from single to double, or even triple for the TFC of stamen extracts, demonstrating the high heterogeneity in phenolics/polyphenols accumulations observed for these medicinal species' organs, and the importance to evaluate these contents prior to their use for further studies (e.g., determination of a biological activity) and/or industrial applications (Table 2).

Table 2. Phytochemical profiles of stamen and perianth extracts from 18 N. nucifera populations originating from various floristic regions from Thailand.

\begin{tabular}{|c|c|c|c|}
\hline Sample & TPC (mg/100 g DW) & TFC (mg/100 g DW) & MAC (mg/100 g DW) \\
\hline S\#1 & $621.6 \pm 1.5^{b}$ & $1474.3 \pm 35.2^{c}$ & $2.47 \pm 0.14^{\mathrm{ab}}$ \\
\hline $\mathrm{S} \# 2$ & $548.7 \pm 4.0^{\mathrm{de}}$ & $1019.5 \pm 69.3^{d}$ & $2.59 \pm 0.11^{\mathrm{a}}$ \\
\hline S\#3 & $553.8 \pm 4.5^{\mathrm{de}}$ & $712.3 \pm 35.9^{f}$ & $1.69 \pm 0.10^{c}$ \\
\hline S\#4 & $542.5 \pm 16.4$ de & $570.6 \pm 1.7^{g}$ & $1.69 \pm 0.02^{\mathrm{c}}$ \\
\hline S\#5 & $492.1 \pm 19.1^{\mathrm{f}}$ & $688.5 \pm 74.1^{\mathrm{f}}$ & $1.63 \pm 0.02^{c}$ \\
\hline S\#6 & $544.7 \pm 4.3^{\mathrm{e}}$ & $575.4 \pm 3.1^{\mathrm{g}}$ & $1.56 \pm 0.08^{\mathrm{cd}}$ \\
\hline S\#7 & $580.7 \pm 5.5^{\mathrm{c}}$ & $1075.7 \pm 0.7^{\mathrm{d}}$ & $1.59 \pm 0.04^{\mathrm{c}}$ \\
\hline S\#8 & $529.4 \pm 7.8^{\mathrm{e}}$ & $1119.5 \pm 78.3^{d}$ & $1.45 \pm 0.04^{\mathrm{de}}$ \\
\hline S\#9 & $559.4 \pm 1.3^{\mathrm{d}}$ & $736.4 \pm 60.7^{\mathrm{f}}$ & $1.51 \pm 0.01^{\mathrm{d}}$ \\
\hline S\#10 & $538.6 \pm 24.5^{\mathrm{def}}$ & $887.4 \pm 24.1^{\mathrm{e}}$ & $1.42 \pm 0.01^{\mathrm{e}}$ \\
\hline S\#11 & $537.7 \pm 6.4^{\mathrm{d}}$ & $909.9 \pm 78.3^{\mathrm{e}}$ & $1.45 \pm 0.04^{\mathrm{d}}$ \\
\hline S\#12 & $543.2 \pm 33.6^{\text {cdef }}$ & $897.8 \pm 4.1^{\mathrm{e}}$ & $1.37 \pm 0.04^{\mathrm{e}}$ \\
\hline S\#13 & $551.9 \pm 1.1^{\mathrm{e}}$ & $904.7 \pm 81.4^{\text {ef }}$ & $1.56 \pm 0.01^{\mathrm{c}}$ \\
\hline S\#14 & $667.5 \pm 21.5^{\mathrm{a}}$ & $1684.3 \pm 34.8^{\mathrm{a}}$ & $2.14 \pm 0.06^{b}$ \\
\hline S\#15 & $663.9 \pm 14.2^{\mathrm{a}}$ & $1673.3 \pm 3.8^{\mathrm{a}}$ & $2.11 \pm 0.18^{b}$ \\
\hline S\#16 & $670.7 \pm 24.9^{a}$ & $1671.9 \pm 7.2^{\mathrm{a}}$ & $2.40 \pm 0.08^{\mathrm{a}}$ \\
\hline S\#17 & $669.4 \pm 30.6^{\mathrm{a}}$ & $1590.9 \pm 4.1^{\mathrm{b}}$ & $2.57 \pm 0.08^{a}$ \\
\hline S\#18 & $664.0 \pm 18.8^{\mathrm{a}}$ & $1620.6 \pm 40.7^{\mathrm{ab}}$ & $2.25 \pm 0.06^{b}$ \\
\hline P\#1 & $187.6 \pm 7.3^{\mathrm{a}}$ & $315.7 \pm 4.1^{\mathrm{a}}$ & $9.06 \pm 0.34^{\mathrm{a}}$ \\
\hline $\mathrm{P \# 2}$ & $189.2 \pm 1.3^{\mathrm{a}}$ & $305.2 \pm 2.6^{b}$ & $5.90 \pm 0.71^{\mathrm{d}}$ \\
\hline P\#3 & $108.1 \pm 24.0^{\mathrm{de}}$ & $162.6 \pm 15.2^{\mathrm{e}}$ & $4.88 \pm 0.46^{\mathrm{de}}$ \\
\hline P\#4 & $166.7 \pm 19.8^{a b c}$ & $182.3 \pm 1.7^{\mathrm{d}}$ & $4.97 \pm 0.61^{\mathrm{de}}$ \\
\hline P\#5 & $152.8 \pm 4.9^{c}$ & $187.4 \pm 6.2^{\mathrm{d}}$ & $5.67 \pm 0.10^{d}$ \\
\hline P\#6 & $112.0 \pm 38.5^{\mathrm{cd}}$ & $176.8 \pm 11.4 \mathrm{de}$ & $4.32 \pm 0.22^{\mathrm{e}}$ \\
\hline P\#7 & $120.9 \pm 4.3^{\mathrm{d}}$ & $168.5 \pm 1.0^{\mathrm{e}}$ & $8.33 \pm 0.93^{\mathrm{ab}}$ \\
\hline P\#8 & $143.5 \pm 2.3^{c}$ & $148.8 \pm 6.2^{\mathrm{e}}$ & $8.45 \pm 2.57^{\mathrm{abcd}}$ \\
\hline P\#9 & $111.1 \pm 1.9^{\mathrm{d}}$ & $138.8 \pm 9.3^{\text {ef }}$ & $4.21 \pm 0.97 \mathrm{de}$ \\
\hline P\#10 & $95.2 \pm 0.9^{\mathrm{e}}$ & $131.2 \pm 7.9^{f}$ & $4.66 \pm 0.42^{\mathrm{de}}$ \\
\hline P\#11 & $86.7 \pm 33.8^{\mathrm{de}}$ & $138.1 \pm 2.4^{\mathrm{f}}$ & $7.08 \pm 0.12^{c}$ \\
\hline $\mathrm{P \# 12}$ & $101.2 \pm 24.9^{\mathrm{de}}$ & $128.1 \pm 5.5^{\mathrm{f}}$ & $7.96 \pm 2.32 \mathrm{abcd}$ \\
\hline P\#13 & $100.3 \pm 6.2 \mathrm{de}$ & $148.5 \pm 2.4^{\mathrm{e}}$ & $4.42 \pm 0.40^{\mathrm{e}}$ \\
\hline P\#14 & $171.2 \pm 6.4^{b}$ & $233.3 \pm 0.3^{c}$ & $8.71 \pm 0.28^{a b}$ \\
\hline P\#15 & $152.1 \pm 3.8^{c}$ & $234.3 \pm 6.9^{c}$ & $8.73 \pm 0.16^{\mathrm{a}}$ \\
\hline P\#16 & $214.4 \pm 42.8^{\mathrm{ab}}$ & $311.9 \pm 1.0^{\mathrm{ab}}$ & $8.41 \pm 0.14^{b}$ \\
\hline P\#17 & $201.7 \pm 14.1^{\mathrm{a}}$ & $310.2 \pm 2.8^{\mathrm{ab}}$ & $8.61 \pm 0.14^{\mathrm{ab}}$ \\
\hline $\mathrm{P \# 18}$ & $233.9 \pm 57.3^{\mathrm{ab}}$ & $285.4 \pm 17.2^{\mathrm{ab}}$ & $8.89 \pm 1.01^{\mathrm{ab}}$ \\
\hline
\end{tabular}

S: stamen; P: perianth; \#i indicate the population number i; TPC: total phenolic content; TFC: total flavonoid content; MAC: monomeric anthocyanin content; DW: dry weigth. Different supercript letters indicate significant differences at $p<0.05$.

The TPC ranged from 95.2 (P\#10) to 233.9 (P\#18) mg/100 g DW gallic acid equivalent for perianth extracts, and from 492.1 (S\#5) to 669.4 (S\#16) $\mathrm{mg} / 100 \mathrm{~g}$ DW gallic acid equivalent for stamen extracts. The TFC ranged from 128.1 (P\#12) to 315.7 (P\#1) mg/100 g DW 
quercetin equivalent for perianth extracts, and from 570.6 (S\#4) to 1,684.3 (S\#14) mg/100 g DW quercetin equivalent for stamen extracts. The MAC ranged from 4.21 (P\#9) to 8.89 (P\#18) mg/100 g DW cyanidin-3-O-glucoside equivalent for perianth extracts, and from 1.37 (S\#12) to 2.59 (S\#1) mg/100 g DW cyanidin-3-O-glucoside equivalent for stamen extracts. From these results, the stamen appeared as a starting material high in TPC and TFC, although perianth was higher in MAC.

The significance of TFC as a key contributor to phytochemical variation was established in a ternary plot, as illustrated by the heatmap distribution, which was markedly shifted in the first bottom triangle (high TFC) for each N. nucifera organ (Figure 3).
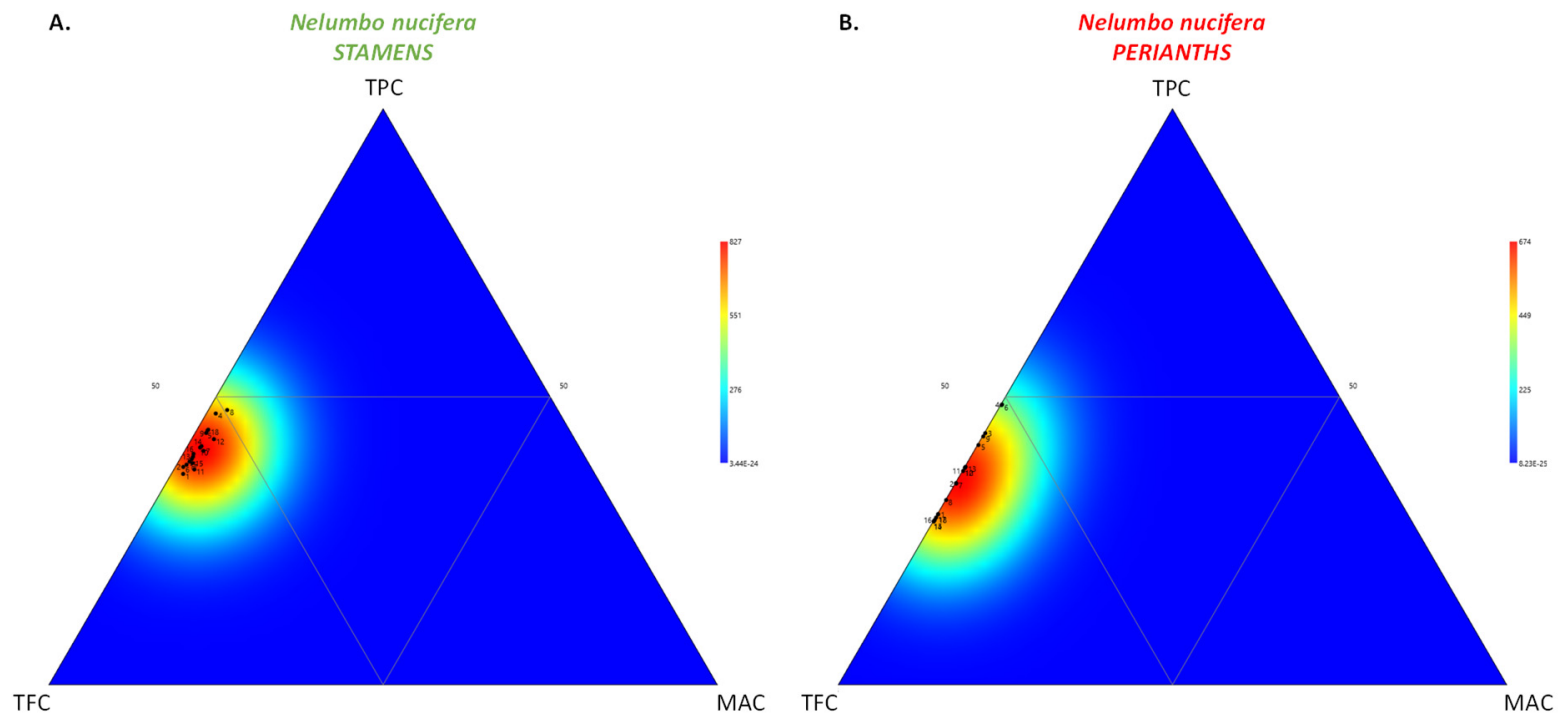

Figure 3. Ternary plot showing the visualization of the relative proportion of TPC, TFC, and TAC within the stamen (A) and perianth (B) extracts of 18 N. nucifera populations originating from various floristic regions from Thailand.

Compared to other organs, few studies have dealt with the TPC, TFC, or MAC of stamen and perianth extracts from $N$. nucifera, but the observed variation ranges are consistent with the few published data [5,12,27,30-33]. Our results confirmed prior observations indicating that their accumulation varies substantially from one organ to another $[10,27,28,30,32,34,35]$. However, it is worth noting that, here, we described for the first time that there is a significant correlation (particularly so for TFCs) between the contents in perianth extract vs stamen extract for each class of phytochemicals. This indicates that, regardless of the organ, the accumulation capacity for a given population in a particular environment remains stable. This is highly intriguing since, in terms of minimum biomass, a rapid evaluation with perianth is easier to perform than with stamen. The relative impacts of these populations' genetic backgrounds and the environment will be fascinating to assess over multiple years on the same site and with a specific population, or using the culture of descendants of the same population on other cultivation sites. Environmental factors, such as climatic and geographic (including growing conditions) factors, in addition to heredity, are well recognized to have a considerable impact on the accumulation of phenolic compounds [36,37].

As our results identified TFC as the main phytochemical class of these stamen and perianth extracts, as well as key contributors to the observed variations, HPLC analyses were performed to offer a comprehensive understanding of the qualitative and quantitative changes (Figure 4, Table S1). 
A.

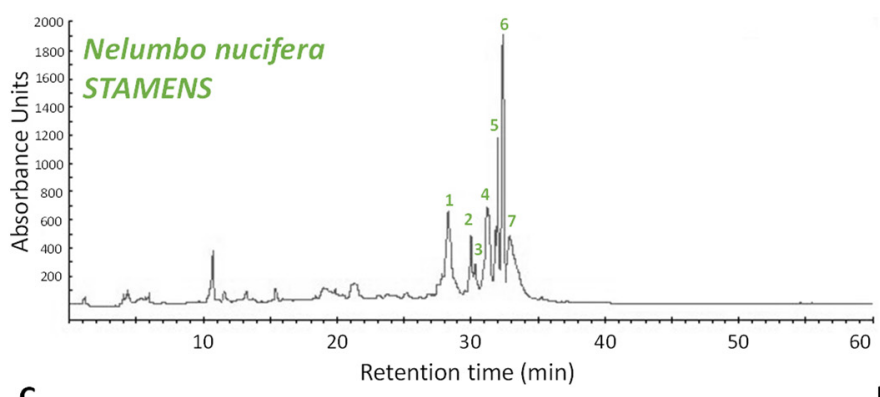

C.

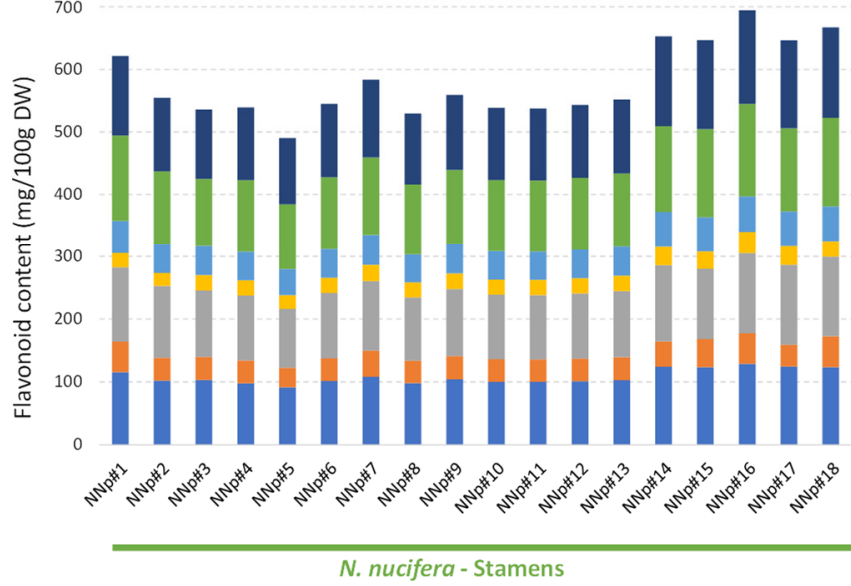

B.

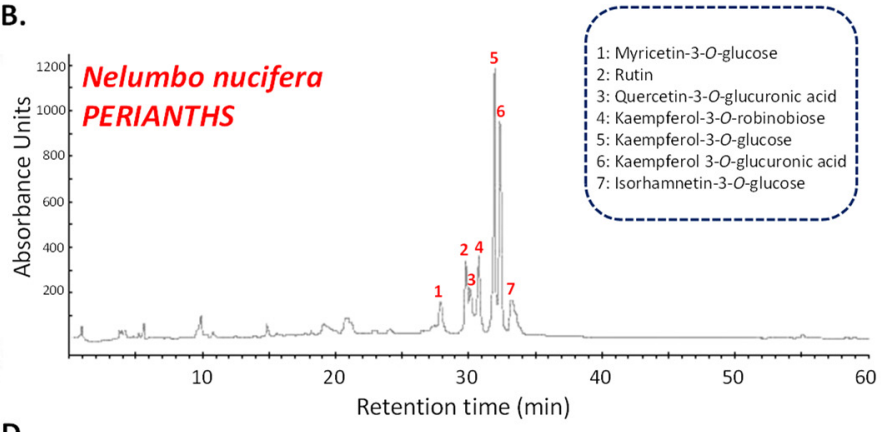

D.

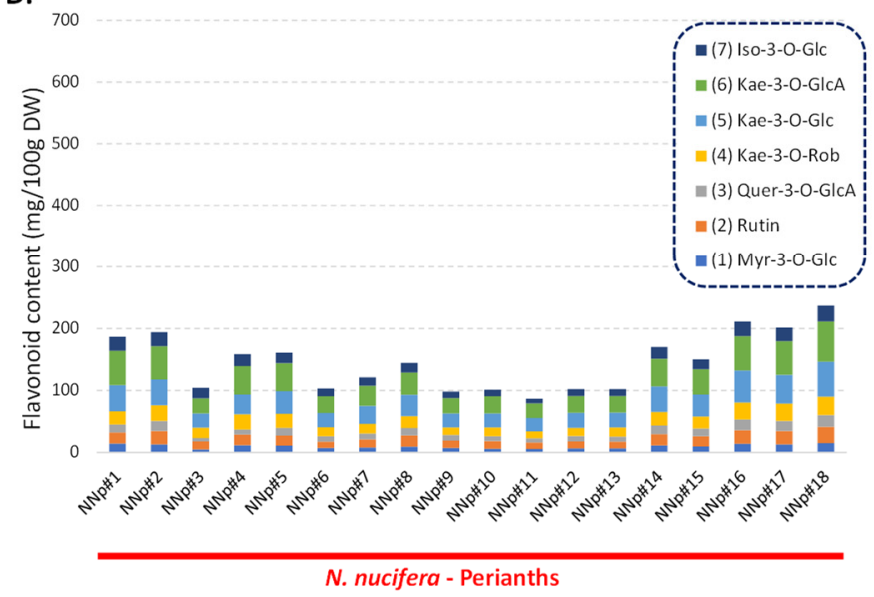

Figure 4. HPLC chromatograms (recorded at $320 \mathrm{~nm}$ ) of the the stamen (A) and perianth (B) extracts of $18 \mathrm{~N}$. nucifera populations originating from various floristic regions from Thailand. Quantification of the main flavonoids in the stamen (C) and perianth (D) extracts of $18 \mathrm{~N}$. nucifera populations originating from various floristic regions from Thailand. Myr-3-O-Glc: myricetin-3-O-glucose; Quer3-O-GlcA: quercetin-3-O-glucuronic acid; Kae-3-O-Rob: kaempferol-3-O-robinobiose; Kae-3-O-Glc: kaempferol-3-O-glucose; Kae 3-O-GlcA: kaempferol 3-O-glucuronic acid; Iso-3-O-Glc: isorhamnetin3-O-glucose; the mean and standard deviation of the concentration of each flavonoid is provided in Table S1.

Individual flavonoid concentrations varied from 5.0 (myricetin-3-O-glucose, P\#3) to 149.9 (isorhamnetin-3-O-glucose, S\#16) $\mathrm{mg} / 100 \mathrm{~g}$ DW in N. nucifera extracts. This analysis confirmed that stamen extracts are richer in flavonoids than perianth extracts. At the population level, the flavonoid content of stamen extracts is fairly balanced, with the predominant flavonoids being myricetin-3-O-glucose, quercetin-3-O-glucuronic acid, kaempferol 3-O-glucuronic acid, and isorhamnetin-3-O-glucose. Perianth extracts, on the other hand, accumulated mostly kaempferol derivatives, such as kaempferol-3-Orobinobiose and kaempferol-3-O-glucose (Figure 4, Table S1). The concentrations found here are comparable to those described by Temviriyanukul et al. [27] for aglycones generated by acidic hydrolysis. The occurrence of the three keampferol glycosides has been previously reported, but no quantification has been performed by the authors [12]. The present study is therefore the first to quantify different flavonoids accumulated in $N$. nucifera stamen and perianth extracts under their native glycosidic forms, which were investigated here at the population level.

Hierarchical clustering analysis (HCA) was applied to identify potential groupings among the diverse samples from the various populations (Figure 5). 


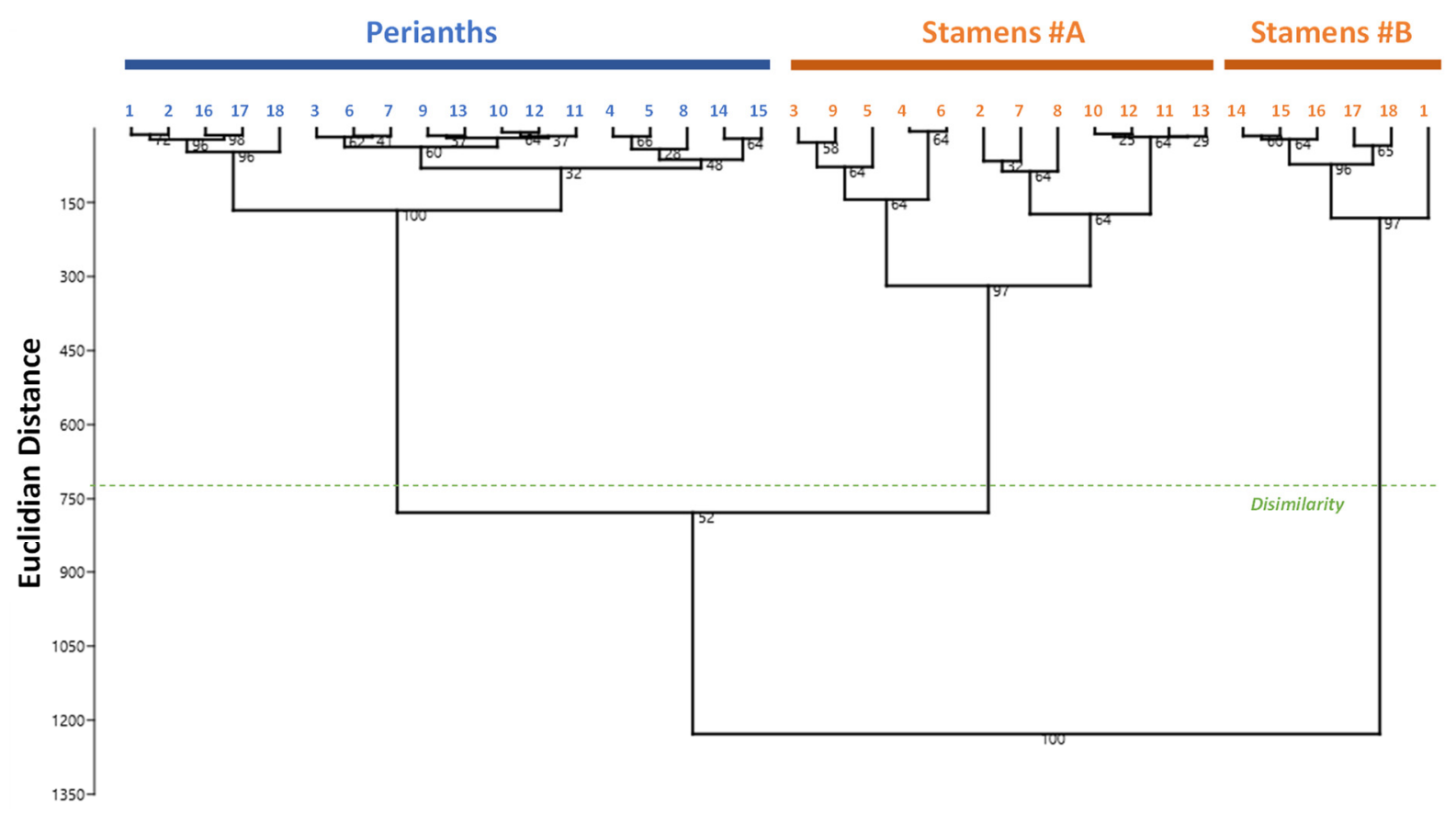

Figure 5. Hierarchical clustering analysis dendrogram according to the phytochemical composition of the stamen and perianth extracts of $18 \mathrm{~N}$. nucifera populations originating from various floristic regions from Thailand. The percentages of replicate trees in which associated samples cluster together in the bootstrap test (percentage of 5000 replicates) are indicated next to the branches.

The hierarchical cluster analysis (HCA) revealed that the clustering occurred primarily at the organ level based on their phytochemical profiles. Perianth extracts were clustered together, whereas stamen extracts were divided into two subgroups based on their different flavonoid concentrations, with cluster stamen\#B containing populations \#1 and \#14-18 being richer in flavonoids. However, no discernable pattern exists to demonstrate the significance of the genetic background factor. Considering the wide geographic distribution of the different $N$. nucifera populations across Thailand's many floristic areas, environmental variables may explain at least some part of the heterogeneity in phytochemical profiles observed.

Altogether, the present results provide a complete picture of the wide phytochemicalparticularly flavonoid-variations observed at the organ level in different $N$. nucifera populations from the floristic regions of Thailand. Because we anticipate that these variations may have an impact on the health-promoting effect of $N$. nucifera, we next investigate how the antioxidant capacity of these extracts varies. Indeed, flavonoids have been shown to have a variety of health-promoting effects through their antioxidant activity [38].

\subsection{Antioxidant Activity}

The antioxidant capacity of the stamen and perianth extracts from the different $N$. nucifera populations to scavenge free radicals was evaluated using two major antioxidant mechanisms: the hydrogen atom transfer (HAT) mechanism evaluated with the ABTS assay, the single electron transfer (SET) mechanism evaluated with the FRAP assay, and the DPPH assay that allowed for the evaluation of both mechanisms [39,40]. The results are summarized in Table 3. 
Table 3. In vitro cell-free antioxidant activity of the stamen and perianth extracts of $18 \mathrm{~N}$. nucifera populations originating from various floristic regions from Thailand.

\begin{tabular}{|c|c|c|c|}
\hline Sample & ABTS ( $\mu$ mol TEAC) & DPPH ( $\mu \mathrm{mol}$ TEAC) & FRAP ( $\mu \mathrm{mol}$ TEAC) \\
\hline S\#1 & $54.2 \pm 2.4^{b c}$ & $185.0 \pm 7.9^{b}$ & $291.5 \pm 2.6^{b}$ \\
\hline S\#2 & $43.2 \pm 1.2^{\mathrm{d}}$ & $148.6 \pm 4.0^{\mathrm{c}}$ & $265.8 \pm 2.5^{\mathrm{d}}$ \\
\hline S\#3 & $33.1 \pm 0.4 \mathrm{gh}$ & $115.1 \pm 1.3^{\text {ef }}$ & $227.7 \pm 5.5^{g}$ \\
\hline S\#4 & $33.6 \pm 1.2 \mathrm{gh}$ & $116.9 \pm 4.0^{\text {ef }}$ & $213.0 \pm 0.7^{\mathrm{h}}$ \\
\hline S\#5 & $29.9 \pm 1.6^{\mathrm{ij}}$ & $104.8 \pm 5.3 \mathrm{gh}$ & $235.4 \pm 5.4 \mathrm{~g}$ \\
\hline S\#6 & $27.4 \pm 0.4^{\mathrm{j}}$ & $96.4 \pm 1.3^{\mathrm{h}}$ & $210.0 \pm 2.3^{h}$ \\
\hline S\#7 & $53.7 \pm 10.4^{\mathrm{abcd}}$ & $183.1 \pm 34.3^{\mathrm{abc}}$ & $281.0 \pm 5.8^{b c}$ \\
\hline S\#8 & $59.0 \pm 2.8^{\mathrm{ab}}$ & $182.1 \pm 50.1^{\mathrm{abcd}}$ & $281.6 \pm 4.3^{c}$ \\
\hline S\#9 & $31.6 \pm 1.8^{\mathrm{hi}}$ & $110.4 \pm 5.8^{\mathrm{fg}}$ & $229.4 \pm 5.6^{\mathrm{g}}$ \\
\hline S\#10 & $35.6 \pm 1.6^{\mathrm{fg}}$ & $123.5 \pm 5.7^{\mathrm{e}}$ & $249.8 \pm 3.8^{\text {ef }}$ \\
\hline S\#11 & $42.4 \pm 1.5^{\mathrm{de}}$ & $145.8 \pm 5.3^{\mathrm{cd}}$ & $246.6 \pm 0.3^{f}$ \\
\hline S\#12 & $39.0 \pm 2.4^{\text {ef }}$ & $134.6 \pm 7.9 \mathrm{de}$ & $253.9 \pm 3.2^{\mathrm{e}}$ \\
\hline $\mathrm{S} \# 13$ & $52.0 \pm 2.9^{c}$ & $177.5 \pm 7.9^{\mathrm{b}}$ & $251.4 \pm 6.7^{\text {ef }}$ \\
\hline S\#14 & $60.2 \pm 0.4^{\mathrm{a}}$ & $195.9 \pm 11.5^{\mathrm{ab}}$ & $317.3 \pm 14.0^{\mathrm{a}}$ \\
\hline S\#15 & $60.5 \pm 0.8^{\mathrm{a}}$ & $202.0 \pm 8.9^{a b}$ & $319.6 \pm 13.1^{\mathrm{a}}$ \\
\hline S\#16 & $58.8 \pm 1.6^{\mathrm{ab}}$ & $183.7 \pm 4.8^{\mathrm{b}}$ & $319.5 \pm 18.9^{\mathrm{a}}$ \\
\hline S\#17 & $59.3 \pm 0.8^{\mathrm{a}}$ & $192.8 \pm 18.3^{\mathrm{ab}}$ & $317.1 \pm 21.1^{\mathrm{ab}}$ \\
\hline S\#18 & $60.2 \pm 0.4^{\mathrm{a}}$ & $204.5 \pm 1.3^{\mathrm{a}}$ & $316.3 \pm 18.6^{a b}$ \\
\hline P\#1 & $25.1 \pm 0.6^{g}$ & $89.0 \pm 1.7^{\mathrm{f}}$ & $158.4 \pm 5.7^{\mathrm{a}}$ \\
\hline P\#2 & $27.1 \pm 0.8^{\mathrm{e}}$ & $95.5 \pm 2.6^{\mathrm{g}}$ & $162.7 \pm 7.5^{\mathrm{a}}$ \\
\hline P\#3 & $31.4 \pm 2.0^{\mathrm{cd}}$ & $109.5 \pm 6.6^{\mathrm{cd}}$ & $70.2 \pm 7.3$ ef \\
\hline P\#4 & $27.7 \pm 1.8^{\text {def }}$ & $97.4 \pm 5.3^{\mathrm{e}}$ & $91.6 \pm 16.9$ ef \\
\hline P\#5 & $27.1 \pm 1.6^{\text {defg }}$ & $95.5 \pm 5.8$ ef & $86.8 \pm 1.8^{f}$ \\
\hline P\#6 & $28.5 \pm 2.0^{\mathrm{de}}$ & $100.2 \pm 6.6^{\mathrm{de}}$ & $77.1 \pm 4.8^{\mathrm{e}}$ \\
\hline $\mathrm{P \# 7}$ & $32.8 \pm 1.6^{\mathrm{c}}$ & $114.1 \pm 5.3^{c}$ & $64.6 \pm 6.1 \mathrm{gh}$ \\
\hline $\mathrm{P \# 8}$ & $33.3 \pm 0.8^{c}$ & $116.0 \pm 2.6^{c}$ & $62.9 \pm 2.1^{g}$ \\
\hline Р\#9 & $36.7 \pm 3.2^{a b c}$ & $127.2 \pm 10.5^{a b c}$ & $55.1 \pm 1.5^{\mathrm{hi}}$ \\
\hline P\#10 & $40.4 \pm 0.4^{\mathrm{a}}$ & $139.3 \pm 1.3^{\mathrm{a}}$ & $50.5 \pm 2.6^{\mathrm{i}}$ \\
\hline P\#11 & $33.1 \pm 0.7^{\mathrm{c}}$ & $115.1 \pm 1.5^{\mathrm{c}}$ & $57.2 \pm 2.3 \mathrm{hi}$ \\
\hline P\#12 & $37.0 \pm 1.2^{b}$ & $128.1 \pm 4.0^{\mathrm{b}}$ & $49.3 \pm 2.1^{\mathrm{i}}$ \\
\hline P\#13 & $39.8 \pm 2.8^{a b}$ & $137.4 \pm 9.2^{\mathrm{ab}}$ & $50.6 \pm 3.1^{\mathrm{i}}$ \\
\hline P\#14 & $25.4 \pm 0.8^{\mathrm{fe}}$ & $89.9 \pm 2.6^{\mathrm{f}}$ & $119.4 \pm 4.6^{\mathrm{d}}$ \\
\hline P\#15 & $25.1 \pm 0.4^{g}$ & $89.0 \pm 1.3^{\mathrm{f}}$ & $118.8 \pm 3.5^{\mathrm{d}}$ \\
\hline P\#16 & $25.4 \pm 0.8^{\mathrm{hg}}$ & $89.9 \pm 2.6^{\mathrm{f}}$ & $157.2 \pm 4.4^{\mathrm{a}}$ \\
\hline $\mathrm{P \# 17}$ & $24.6 \pm 0.4^{g}$ & $87.1 \pm 1.1^{\mathrm{f}}$ & $144.0 \pm 3.2^{b}$ \\
\hline P\#18 & $24.0 \pm 0.3^{g}$ & $85.3 \pm 1.7^{\mathrm{f}}$ & $138.3 \pm 0.9^{\mathrm{c}}$ \\
\hline
\end{tabular}

S: stamen; P: perianth; \#i indicate the population number i; ABTS: 2,2-azinobis (3-ethylbenzthiazoline-6-sulphonic acid; DPPH: 2,2-diphenyl-1-picrylhydrazyl; FRAP: ferric reducing antioxidant power. Different supercript letters indicate significant differences at $p<0.05$.

Here (Table 3), the ABTS radical scavenging activity ranged from 24.0 (P\#18) to 40.4 (P\#10) $\mu \mathrm{mol} \mathrm{TE} / \mathrm{g}$ DW for the perianth extracts, and from 27.4 (S\#6) to 60.5 (S\#15) $\mu \mathrm{mol}$ $\mathrm{TE} / \mathrm{g}$ DW for the stamen extracts. The DPPH free radical scavenging activity ranged from 85.3 (P\#18) to 139.3 (P\#10) $\mu \mathrm{mol} \mathrm{TE} / \mathrm{g}$ DW for the perianth extracts, and from 96.4 (S\#6) to 204.5 (S\#18) $\mu \mathrm{mol}$ TE/g DW for the stamen extracts. The FRAP reducing power ranged from 49.3 (P\#12) to 162.7 (P\#2) $\mu \mathrm{mol} \mathrm{TE} / \mathrm{g}$ DW for the perianth extracts, and from 210.0 (S\#6) to 319.6 (S\#16) $\mu \mathrm{mol} \mathrm{TE} / \mathrm{g}$ DW for the stamen extracts. The present results revealed the importance of the HAT antioxidant mechanism over the ET mechanism, as shown in Figure 6, with the FRAP assay for stamen extract (Figure 6A) and both FRAP and DPPH assays for perianth extracts contributing the most to their antioxidant capacity (Figure 6B). 
A.

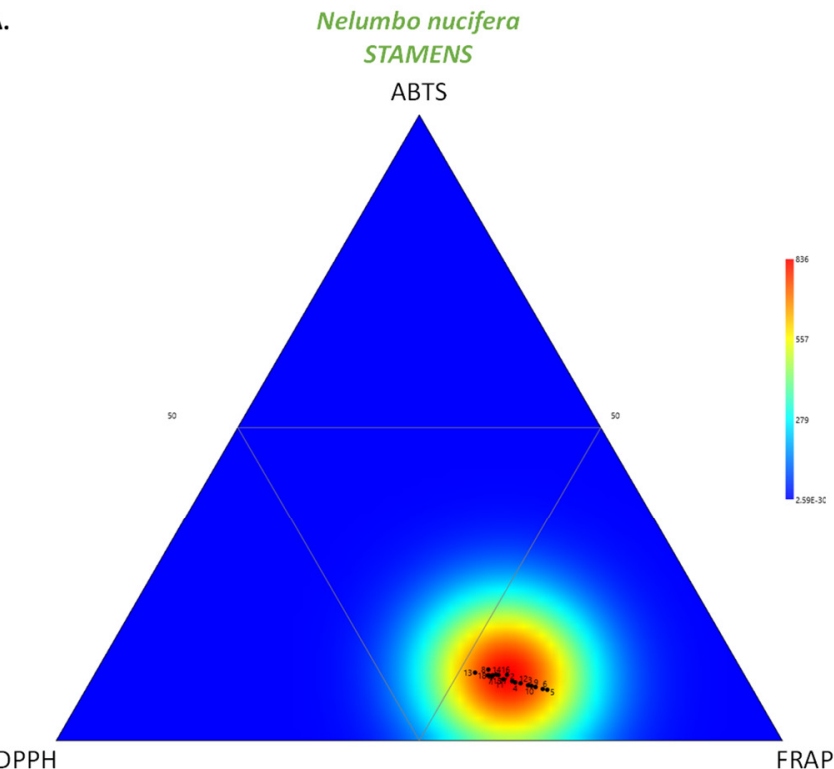

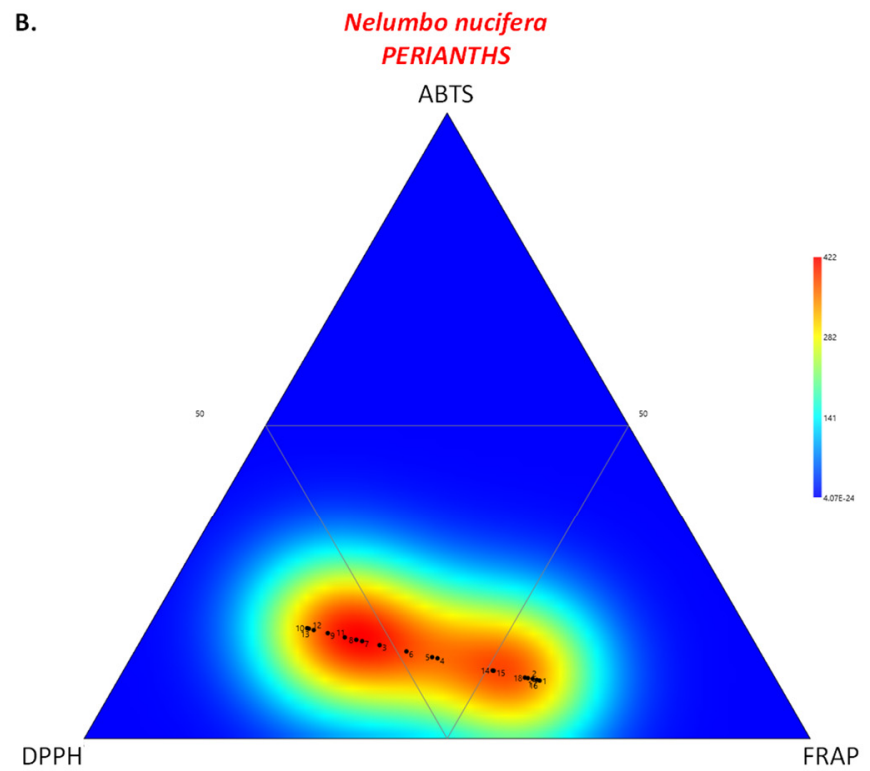

Figure 6. Ternary plot showing the visualization of the relative contribution of the different in vitro assays (ABTS, DPPH and FRAP) to the antioxidant capacitiy of the stamen (A) and perianth (B) extracts of $18 \mathrm{~N}$. nucifera populations originating from various floristic regions from Thailand.

Our results are consistent with the work of Jung et al. [12], who showed that flavonoids from $N$. nucifera stamen extract, particularly the kaempferol glycosides, exhibit strong radical scavenging capacity. The observed prominence of the HAT mechanism is consistent with the observation that flavonoids prefer HAT-based reactions to ET-based reactions when quenching free radicals [40-42]. In contrast, Temviriyanukul et al. [27] reported that the ET mechanism contributed the most to the antioxidant capacity of their $N$. nucifera extract. Other compounds, particularly phenolics [40,41], which contribute mainly through an ET-based mechanism, may also contribute to this antioxidant action. In support of our results, Lin et al. [8] showed that flavonoids mainly contributed to antioxidant activities in N. nucifera compared to other phenolics.

\subsection{Correlation Analysis}

Different variables were used in a principal component analysis (PCA) to extract relevant connections between the metabolic composition and antioxidant activities within the stamen and perianth extracts from different $N$. nucifera natural populations (Figure 7).

The generated biplot representation explained $99.75 \%$ of the initial variability (Figure 5). The TFC and the FRAP antioxidant assay are the key contributing elements to the discrimination along the component 1 axis, which accounts for $97.42 \%$ of the initial variability (Figure S1). The second component axis, on the other hand, accounted for only $2.33 \%$. As a consequence of this PCA, two different clusters were shown to be significantly different from one another based on their TFC and FRAP antioxidant activity. Remarkably, these clusters distinguished stamen extracts, which are high in flavonoids and have high FRAP antioxidant activity, from perianth extracts, which contribute less to both parameters. This study demonstrated the value of stamen as a starting material for applications based on antioxidant flavonoids derived from $N$. nucifera.

Pearson correlation coefficients (PCC) were calculated to assess the relationship between each phytochemical and antioxidant activity (Table 4). 


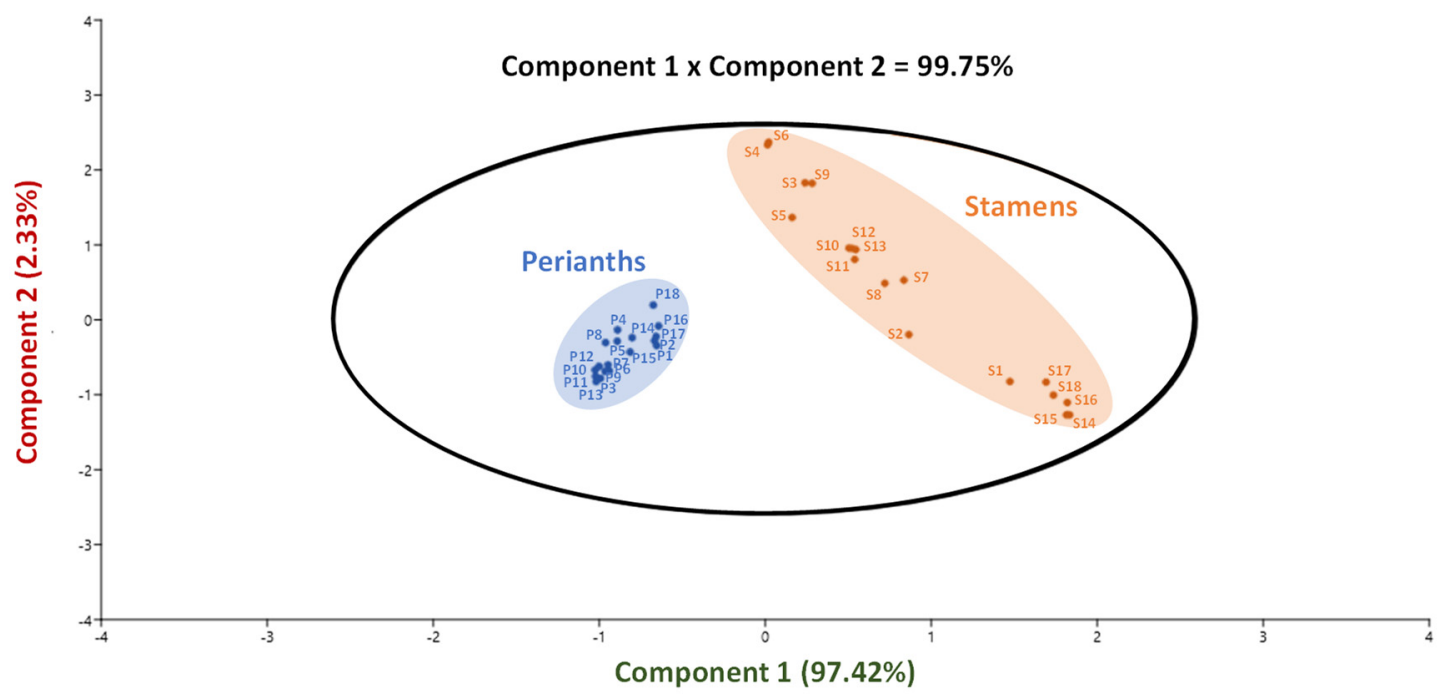

Figure 7. Principal component analysis (PCA) linking the phytochemical profile and antioxidant capacity of the stamen and perianth extracts of $18 \mathrm{~N}$. nucifera populations originating from various floristic regions from Thailand. Variance of component $1=97.42 \%$ and component $=2.33 \%$. S: stamen extract; P: perianth extract; each number in blue represents the different populations. The corresponding loading score plots for components 1 and 2 are presented in Figure S1.

Table 4. Pearson coefficient correlation) between phytochemical profiles and antioxidant activities of the stamen and perianth extracts of $18 \mathrm{~N}$. nucifera populations.

\begin{tabular}{cccc}
\hline Compound & ABTS & DPPH & FRAP \\
\hline TPC & $0.699^{* * *}$ & $0.698^{* * *}$ & $0.969^{* * *}$ \\
TFC & $0.860^{* * *}$ & $0.853^{* * *}$ & $0.941^{* * *}$ \\
MAC & $-0.609^{* * *}$ & $-0.616^{* * *}$ & $-0.710^{* * *}$ \\
Myr-3-O-Glc & $0.719^{* * *}$ & $0.719^{* * *}$ & $0.950^{* * *}$ \\
Rutin & $0.666^{* * *}$ & $0.668^{* * *}$ & $0.957^{* * *}$ \\
Quer-3-O-GlcA & $0.704^{* * *}$ & $0.705^{* * *}$ & $0.946^{* * *}$ \\
Kae-3-O-Rob & $0.338^{*}$ & $0.310 \mathrm{~ns}$ & $0.753^{* * *}$ \\
Kae-3-O-Glc & $0.453^{* *}$ & $0.442^{* * *}$ & $0.873^{* * *}$ \\
Kae-3-O-GlcA & $0.681^{* * *}$ & $0.678^{* * *}$ & $0.977^{* * *}$ \\
Iso-3-O-Glc & $0.716^{* * *}$ & $0.716^{* * *}$ & $0.955^{* * *}$ \\
\hline
\end{tabular}

*** significant $p<0.001 ;{ }^{* *}$ significant $p<0.01 ;{ }^{*}$ significant $p<0.05 ;$ ns: not significant.

This correlation analysis clearly established the strength of the association between TPC, TFC (including each individual flavonoid), and MAC and the several antioxidant assays. Significant correlations between various classes of phytochemicals and the different antioxidant tests were noted. This emphasized the fact that the antioxidant capability of an extract is generally the result of complex phytochemical combinations rather than the action of a single molecule [43]. Considering the importance of the HAT antioxidant mechanism to the antioxidant capacity of the $N$. nucifera extracts, the strongest and most significant correlations linking TPC, TFC, as well as myricetin-3-O-glucose, rutin, quercetin-3-Oglucuronic acid, kaempferol-3-O-glucuronic acid, and isorhamnetin-3-O-glucose content to the FRAP assay are certainly more notable. The specific contributions of the kaempferol glycosides isolated from $N$. nucifera stamen to the strong radical scavenging capacity of this extract have already been resolved [12]. The present correlation analysis emphasized that the roles of the other flavonoids should also be investigated.

\section{Materials and Methods}

\subsection{Chemicals and Reagents}

The solvents and reagents for extraction as well as for HPLC analysis were of analytical grade or the highest available purity (Thermo Fischer Scientific, Illkirch, France). The 
deionized water was purified using the Milli-Q water-purification system (Merck Millipore Fontenay sous Bois, Paris, France). All of the prepared solutions for HPLC were filtered through $0.45-\mu \mathrm{m}$ nylon syringe membranes before use. The standards were purchased from Extrasynthese (Genay, France).

\subsection{Plant Materials}

The living plant materials of $18 \mathrm{~N}$. nucifera populations were collected from the floristic regions in Thailand, including Northern (N), North-Eastern (NE), Central (C), SouthEastern (SE), Eastern (E), South-Western (SW), and Peninsula (PEN). After reviewing the literature as well as information about the $N$. nucifera herbarium specimens, the targeted populations in various localities covering every floristic region in the country were searched, in order to find living specimens in the fields. The collected plant samples were identified at the species level using the taxonomic key and description in the existing Floras [1,2], and compared with the herbarium specimens kept at Forest Herbarium (BKF), Bangkok, Thailand, by Prof. Kasin Suvatabandhu from Herbarium, Chulalongkorn University, (BCU). Herbarium abbreviations are used according to Thiers [44]. The stamen and perianth from 18 populations of $N$. nucifera were air-dried and prepared following World Health Organization recommendations [45].

\subsection{Extraction}

The dried stamen or perianth samples (100 mg/sample) were placed in $5 \mathrm{~mL}$ quartz tubes equipped with a vapor condenser, then extracted by ultrasound-assisted extraction in $1 \mathrm{~mL} \mathrm{90 \%} \mathrm{(v/v)} \mathrm{aqEtOH} \mathrm{in} \mathrm{the} \mathrm{USC1200TH} \mathrm{ultrasonic} \mathrm{bath} \mathrm{(Prolabo,} \mathrm{Fontenay-sous-Bois,}$ France) following the optimized extraction conditions: $30 \mathrm{kHz}$ frequency at $45{ }^{\circ} \mathrm{C}$ for $45 \mathrm{~min}$ [33]. Then, the extract was centrifuged for $15 \mathrm{~min}$ at $5000 \times g$ (Heraeus Biofuge Stratos, Thermo Scientific, Illkirch, France). The obtained supernatant was filtered using 0.45- $\mu \mathrm{m}$ nylon syringe membranes (Merck Millipore, Saint-Quentin Fallavier, France). Flavonoid enrichment was then performed through the additional DAX-8 (Merck Millipore, Saint-Quentin Fallavier, France) macroporous resin purification step as described in the previously study [33].

\subsection{Determination of Total Phenolic Content (TPC)}

The TPC was measured following the Folin-Ciocalteu protocol and microplate spectrophotometry, as previously described by Tungmunnithum et al. [46]. Absorbance was then measured at $650 \mathrm{~nm}$ using a spectrophotometer (BioTek ELX800 Absorbance Microplate Reader, BioTek Instruments, Colmar, France). After that, the standard curve $\left(0-40 \mu \mathrm{g} / \mathrm{mL} ; \mathrm{R}^{2}=0.998\right)$ of gallic acid (Merck, Saint-Quentin Fallavier, France) was employed to express the total phenolic content in $\mathrm{mg}$ of gallic acid equivalents/g DW (mg GAE/100 g dry weight (DW)).

\subsection{Determination of Total Flavonoid Content (TFC)}

The TFC was examined following the colorimetric aluminum trichloride $\left(\mathrm{AlCl}_{3}\right)$ method [33]. The $200 \mu \mathrm{L}$ mixture was prepared in a microplate using $20 \mu \mathrm{L}$ of extract sample, $10 \mu \mathrm{L}$ of potassium acetate $1 \mathrm{M}, 10 \mu \mathrm{L}$ of $\mathrm{AlCl}_{3}(10 \%(w / v))$, as well as $160 \mu \mathrm{L}$ of deionized water. Subsequently, the microplate reader (Multiskan GO, Thermo Fischer Scientific, Illkirch, France) was employed to measure the absorbance at $415 \mathrm{~nm}$ after $30 \mathrm{~min}$ of incubation in the dark at $25^{\circ} \mathrm{C}$. The TFC was expressed in $\mathrm{mg} / 100 \mathrm{~g}$ dry weight (DW) of quercetin equivalent using the five-point calibration line (linearity range from 0 to $40 \mathrm{~g} / \mathrm{mL}$ quercetin concentration with the $\mathrm{R}^{2}$ of 0.998 ).

\subsection{Determination of Total Anthocyanin Content (TAC)}

The TAC was determined using the colorimetric method following the previous study [47]. Absorbance was then measured at 510 and $700 \mathrm{~nm}$ using a spectrophotometer (BioTek ELX800 Absorbance Microplate Reader, BioTek Instruments, Colmar, France). The 
standard curve $\left(0-100 \mu \mathrm{g} / \mathrm{mL}, \mathrm{R}^{2}=0.999\right)$ of cyanidin-3-O-glucoside (Merck, Saint-Quentin Fallavier, France) was employed to express the total anthocyanin content in $\mathrm{mg}$ of cyanidin3-O-glucoside equivalents/ g DW (mg CAE/100 g DW).

\subsection{High-Performance Liquid Chromatography (HPLC) Analysis}

The high-performance liquid chromatography system composed of the autosampler, Varian (Les Ulis, France) Prostar 230 pump, as well as the Varian Prostar 335 photodiode array detector was used to analyze and controlled with the Galaxie software (Varian v1.9.3.2). The separation was then carried out on the Purospher RP-18 column $(250 \times 4.0 \mathrm{~mm}$ internal diameter; $5 \mu \mathrm{m}$ ) (Merck Chemicals, Molsheim, France) at $40{ }^{\circ} \mathrm{C}$. The mobile phase consisted of the mixture of methanol (solvent A) and HPLC grade water (solvent B), which were acidified with $0.05 \%$ formic acid. Then, the linear gradient, from 0 to $60 \mathrm{~min}$ was applied to this mobile phase variation, ranging from the 5:95 $(v / v)$ to 100:0 $(v / v)$ mixture of solvents A and $B$, respectively, using a flow rate of $1.30 \mathrm{~mL} / \mathrm{min}$. The injection volume was $3 \mu \mathrm{L}$, and the maximum back pressure was 110 bar. Detection was performed at $320 \mathrm{~nm}$. The flavonoid compounds were identified by comparison with authentic standards (Sigma Aldrich).

\subsection{In Vitro Cell Free Antioxidant Assays}

The in vitro cell free antioxidant assays, including DPPH (2,2-diphenyl-1-picrylhydrazyl), FRAP (Ferric Reducing Antioxidant Power) as well as ABTS (2,2-azinobis(3-ethylbenzthiazoline6-sulphonic acid) assays, were examined to evaluate the antioxidant activity of the extract samples following the protocols adapted to the microplate reader (Multiskan GO, Thermo Fischer Scientific, Illkirch, France), as previously described [33,36].

\subsection{Statistical Analysis}

Statistical analyses were performed using the XLSTAT 2019 suite (Addinsoft, Paris, France) and the PAST4.0 [48]. The data composed of at least the three independent replicates were presented in the form of mean and standard deviation. The Student's t-test was performed for statistical comparative analysis. Significant differences at $p<0.05,0.01$ as well as 0.001 were presented using ${ }^{*}$, , and ${ }^{* * *}$, respectively. Different letters were employed to indicate the significant thresholds at $p<0.05$.

\section{Conclusions}

To recapitulate, the studied 18 populations of $N$. nucifera obtained from their natural habitats throughout the floristic regions of Thailand displayed a high heterogeneity in terms of their phenolics/polyphenols accumulations observed in perianth and stamen. Furthermore, this analysis showed that flavonoids are the main phytochemical class of these extracts, and that the stamen is richer in flavonoids than perianth. Besides, this is also the first description of the significant correlation between the phytochemical contents in perianth and stamen extracts. In addition, the in vitro, cell-free antioxidant approaches point out that the antioxidant capacity of these $N$. nucifera populations is mainly mediated by a hydrogen atom transfer mechanism. The current finding also emphasized that the antioxidant potential of the extracts is the result of the complex phytochemical combinations as opposed to a single molecule. This present research offers frontier knowledge on the phytochemical diversity and antioxidant potential of the perianth and stamen from $N$. nucifera natural populations covering all floristic regions of Thailand, to open the door for phytopharmaceutical sectors seeking potential raw plant material/plant organs to design and develop their different products.

Supplementary Materials: The following supporting information can be downloaded, Figure S1: Loading scores of the component 1 and component 2 of the PCA (presented in Figure 5) linking the phytochemical profile and antioxidant capacity of the stamen and perianth extracts of $18 \mathrm{~N}$. nucifera populations originating from various floristic regions from Thailand; Table S1: HPLC quantification of the main flavonoids in the stamen (A) and perianth (B) extracts of $18 \mathrm{~N}$. nucifera populations originating from various floristic regions from Thailand. 
Author Contributions: Conceptualization, D.T. and C.H.; methodology, D.T., S.D. and C.H.; software, D.T. and C.H.; validation, D.T. and C.H.; formal analysis, D.T. and C.H.; investigation, D.T., S.D. and C.H.; resources, D.T. and C.H.; data curation, D.T. and C.H.; writing-original draft preparation, D.T. and C.H.; writing-review and editing, D.T., S.D. and C.H.; visualization, D.T. and C.H.; supervision, D.T. and C.H.; project administration, D.T. and C.H.; funding acquisition, D.T. and C.H. All authors have read and agreed to the published version of the manuscript.

Funding: This research project is supported by Mahidol University (Basic Research Fund: fiscal year 2022). This research was supported by Cosmetosciences, a global training and research program dedicated to the cosmetic industry. Located in the heart of the Cosmetic Valley, this program led by University of Orléans is funded by the Région Centre-Val de Loire.

Institutional Review Board Statement: Not applicable.

Informed Consent Statement: Not applicable.

Data Availability Statement: All the data supporting the findings of this study are included in this article.

Acknowledgments: D.T. gratefully thanks Mahidol University, Thailand. This research project is supported by Mahidol University (Basic Research Fund: fiscal year 2022). C.H. and D.T. gratefully acknowledge the support of Campus France through the PHC SIAM (PNPIA, Project 44926WK). D.T. and C.H. acknowledge Le Studium Institute for Advance Study for its support. D.T. and C.H. gratefully acknowledge the support of the French Government via the French Embassy in Thailand in the form of the Junior Research Fellowship Program 2018. S.D. acknowledges the research fellowship of the Loire Valley Region.

Conflicts of Interest: The authors declare no conflict of interest.

Sample Availability: Samples of the compounds are available from the authors.

\section{References}

1. Dezhi, F.; Wiersema, J.H. Nelumbo nucifera. In Flora of China; Science Press: Beijing, China; Missouri Botanical Garden Press: St. Louis, MO, USA, 2001; p. 1.

2. Chayamarit, K.; Balslav, H.; Esser, H.J. Flora of Thailand; 14/4; Chayamarit, K., Balslav, H., Eds.; The Forest Herbarium, Royal Forest Department: Bangkok, Thailand, 2020; ISBN 9786163165923.

3. Shen-Miller, J.; Mudgett, M.B.; Schopf, J.W.; Clarke, S.; Berger, R. Exceptional Seed Longevity and Robust Growth: Ancient Sacred Lotus from China. Am. J. Bot. 1995, 82, 1367-1380. [CrossRef]

4. Sikarwar, R.L.S. Angiosperm diversity assessment of Chitrakootthe legendary place of Vindhyan range. India J. Econ. Taxon. Bot. 2014, 38, 563-619.

5. Tungmunnithum, D.; Pinthong, D.; Hano, C. Flavonoids from Nelumbo nucifera Gaertn., a Medicinal Plant: Uses in Traditional Medicine, Phytochemistry and Pharmacological Activities. Medicines 2018, 5, 127. [CrossRef]

6. Tungmunnithum, D.; Renouard, S.; Drouet, S.; Blondeau, J.-P.; Hano, C. A Critical Cross-Species Comparison of Pollen from Nelumbo nucifera Gaertn. vs. Nymphaea lotus L. for Authentication of Thai Medicinal Herbal Tea. Plants 2020, 9, 921. [CrossRef]

7. Seebens, H.; Blackburn, T.M.; Dyer, E.E.; Genovesi, P.; Hulme, P.E.; Jeschke, J.M.; Pagad, S.; Pyšek, P.; Winter, M.; Arianoutsou, M.; et al. No saturation in the accumulation of alien species worldwide. Nat. Commun. 2017, 8, 14435. [CrossRef]

8. Lin, H.Y.; Kuo, Y.H.; Lin, Y.L.; Chiang, W. Antioxidative effect and active components from leaves of lotus (Nelumbo nucifera). J. Agric. Food Chem. 2009, 57, 6623-6629. [CrossRef] [PubMed]

9. Sheikh, S.A. Ethno-medicinal uses and pharmacological activities of lotus (Nelumbo nucifera). J. Med. Plants Stud. $2014,2,42-46$.

10. Lee, J.S.; Shukla, S.; Kim, J.A.; Kim, M. Anti-angiogenic effect of Nelumbo nucifera leaf extracts in human umbilical vein endothelial cells with antioxidant potential. PLOS ONE 2015, 10, e0118552. [CrossRef]

11. Zhu, M.Z.; Wu, W.; Jiao, L.L.; Yang, P.F.; Guo, M.Q. Analysis of flavonoids in lotus (Nelumbo nucifera) leaves and their antioxidant activity using macroporous resin chromatography coupled with LC-MS/MS and antioxidant biochemical assays. Molecules 2015, 20, 10553-10565. [CrossRef]

12. Jung, H.A.; Kim, J.E.; Chung, H.Y.; Choi, J.S. Antioxidant principles of Nelumbo nucifera stamens. Arch. Pharm. Res. 2003, 26, 1. [CrossRef]

13. Le, B.; Anh, P.T.; Yang, S.H. Polysaccharide Derived from Nelumbo nucifera Lotus Plumule Shows Potential Prebiotic Activity and Ameliorates Insulin Resistance in HepG2 Cells. Polymers 2021, 13, 1780. [CrossRef]

14. Wu, Q.; Zhao, K.; Chen, Y.; Ouyang, Y.; Feng, Y.; Li, S.; Zhang, L.; Feng, N. Effect of lotus seedpod oligomeric procyanidins on AGEs formation in simulated gastrointestinal tract and cytotoxicity in Caco-2 cells. Food Funct. 2021, 12, 3527-3538. [CrossRef]

15. Chen, H.; Sun, K.; Yang, Z.; Guo, X.; Wei, S. Identification of Antioxidant and Anti- $\alpha$-amylase Components in Lotus (Nelumbo nucifera, Gaertn.) Seed Epicarp. Appl. Biochem. Biotechnol. 2018, 187, 677-690. [CrossRef] [PubMed] 
16. Zhu, M.; Liu, T.; Zhang, C.; Guo, M. Flavonoids of Lotus (Nelumbo nucifera) Seed Embryos and Their Antioxidant Potential. J. Food Sci. 2017, 82, 1834-1841. [CrossRef]

17. Tan, S.-J.; Lee, C.-K.; Gan, C.-Y.; Olalere, O.A. Statistical Optimization of Flavonoid and Antioxidant Recovery from Macerated Chinese and Malaysian Lotus Root (Nelumbo nucifera) Using Response Surface Methodology. Molecules 2021, 26, 2014. [CrossRef]

18. Rai, S.; Wahile, A.; Mukherjee, K.; Saha, B.P.; Mukherjee, P.K. Antioxidant activity of Nelumbo nucifera (sacred lotus) seeds. J. Ethnopharmacol. 2006, 104, 322-327. [CrossRef]

19. Jiang, X.L.; Wang, L.; Wang, E.J.; Zhang, G.L.; Chen, B.; Wang, M.K.; Li, F. Flavonoid glycosides and alkaloids from the embryos of Nelumbo nucifera seeds and their antioxidant activity. Fitoterapia 2018, 125, 184-190. [CrossRef] [PubMed]

20. Ahn, J.H.; Kim, E.S.; Lee, C.; Kim, S.; Cho, S.H.; Hwang, B.Y.; Lee, M.K. Chemical constituents from Nelumbo nucifera leaves and their anti-obesity effects. Bioorg. Med. Chem. Lett. 2013, 23, 3604-3608. [CrossRef] [PubMed]

21. Li, F.; Sun, X.Y.; Li, X.W.; Yang, T.; Qi, L.W. Enrichment and separation of quercetin-3-O- $\beta$-D-glucuronide from lotus leaves (Nelumbo nucifera gaertn.) and evaluation of its anti-inflammatory effect. J. Chromatogr. B Anal. Technol. Biomed. Life Sci. 2017, 1040, 186-191. [CrossRef] [PubMed]

22. Zhang, C.; Deng, J.; Liu, D.; Tuo, X.; Yu, Y.; Yang, H.; Wang, N. Nuciferine Inhibits Proinflammatory Cytokines via the PPARs in LPS-Induced RAW264.7 Cells. Molecules 2018, 23, 2723. [CrossRef]

23. Kim, S.; Hong, K.-B.; Jo, K.; Suh, H.J. Quercetin-3-O-glucuronide in the Ethanol Extract of Lotus Leaf (Nelumbo nucifera) Enhances Sleep Quantity and Quality in a Rodent Model via a GABAergic Mechanism. Molecules 2021, 26, 3023. [CrossRef]

24. Park, S.H.; Oh, J.; Jo, M.; Kim, J.K.; Kim, D.S.; Kim, H.G.; Yoon, K.; Yang, Y.; Geum, J.-H.; Kim, J.-E.; et al. Water Extract of Lotus Leaf Alleviates Dexamethasone-Induced Muscle Atrophy via Regulating Protein Metabolism-Related Pathways in Mice. Molecules 2020, 25, 4592. [CrossRef] [PubMed]

25. Huang, B.; Zhu, L.; Liu, S.; Li, D.; Chen, Y.; Ma, B.; Wang, Y. In vitro and in vivo evaluation of inhibition activity of lotus (Nelumbo nucifera Gaertn.) leaves against ultraviolet B-induced phototoxicity. J. Photochem. Photobiol. B Biol. 2013, 121, 1-5. [CrossRef]

26. Cho, S.; Cho, H.W.; Woo, K.W.; Jeong, J.; Lim, J.; Park, S.; Seo, M.; Lim, S. Nelumbo nucifera Receptaculum Extract Suppresses Angiotensin II-Induced Cardiomyocyte Hypertrophy. Molecules 2019, 24, 1647. [CrossRef] [PubMed]

27. Temviriyanukul, P.; Sritalahareuthai, V.; Promyos, N.; Thangsiri, S.; Pruesapan, K.; Srinuanchai, W.; Nuchuchua, O.; Siriwan, D.; On-nom, N.; Suttisansanee, U. The Effect of Sacred Lotus (Nelumbo nucifera) and Its Mixtures on Phenolic Profiles, Antioxidant Activities, and Inhibitions of the Key Enzymes Relevant to Alzheimer's Disease. Molecules 2020, 25, 3713. [CrossRef] [PubMed]

28. Tungmunnithum, D.; Thongboonyou, A.; Pholboon, A.; Yangsabai, A. Flavonoids and Other Phenolic Compounds from Medicinal Plants for Pharmaceutical and Medical Aspects: An Overview. Medicines 2018, 5, 93. [CrossRef]

29. Drouet, S.; Garros, L.; Hano, C.; Tungmunnithum, D.; Renouard, S.; Hagège, D.; Maunit, B.; Lainé, É. A Critical View of Different Botanical, Molecular, and Chemical Techniques Used in Authentication of Plant Materials for Cosmetic Applications. Cosmetics 2018, 5, 30. [CrossRef]

30. Li, S.-S.; Wu, J.; Chen, L.-G.; Du, H.; Xu, Y.-J.; Wang, L.-J.; Zhang, H.-J.; Zheng, X.-C.; Wang, L.-S. Biogenesis of C-glycosyl flavones and profiling of flavonoid glycosides in lotus (Nelumbo nucifera). PLoS ONE 2014, 9, e108860. [CrossRef]

31. Shim, S.-Y.; Park, J.-R.; Byun, D.-S. Kaempferol isolated from Nelumbo nucifera stamens inhibits phosphorylation of ERK $1 / 2$, Syk, and Lyn in FceRI-mediated allergic reaction. Food Sci. Biotechnol. 2015, 24, 1475-1480. [CrossRef]

32. Jitsaeng, K.; Sungthong, B. Antioxidant Activity and Total Phenolic Contents of Various Parts from Two Cultivars of Nelumbo nucifera Gaertn. J. Sci. Technol. 2017, 36, 154-160.

33. Tungmunnithum, D.; Drouet, S.; Kabra, A.; Hano, C. Enrichment in Antioxidant Flavonoids of Stamen Extracts from Nymphaea lotus L. Using Ultrasonic-Assisted Extraction and Macroporous Resin Adsorption. Antioxidants 2020, 9, 576. [CrossRef]

34. Chen, S.; Fang, L.; Xi, H.; Guan, L.; Fang, J.; Liu, Y.; Wu, B.; Li, S. Simultaneous qualitative assessment and quantitative analysis of flavonoids in various tissues of lotus (Nelumbo nucifera) using high performance liquid chromatography coupled with triple quad mass spectrometry. Anal. Chim. Acta 2012, 724, 127-135. [CrossRef]

35. Deng, J.; Fu, Z.; Chen, S.; Damaris, R.N.; Wang, K.; Li, T.; Yang, P. Proteomic and Epigenetic Analyses of Lotus (Nelumbo nucifera) Petals Between Red and White cultivars. Plant Cell Physiol. 2015, 56, 1546-1555. [CrossRef] [PubMed]

36. Drouet, S.; Abbasi, B.H.; Falguières, A.; Ahmad, W.S.; Ferroud, C.; Doussot, J.; Vanier, J.R.; Lainé, E.; Hano, C. Single Laboratory Validation of a Quantitative Core Shell-Based LC Separation for the Evaluation of Silymarin Variability and Associated Antioxidant Activity of Pakistani Ecotypes of Milk Thistle (Silybum Marianum L.). Molecules 2018, 23, 904. [CrossRef]

37. Garros, L.; Drouet, S.; Corbin, C.; Decourtil, C.; Fidel, T.; Lebas de Lacour, J.; Leclerc, E.A.; Renouard, S.; Tungmunnithum, D.; Doussot, J.; et al. Insight into the Influence of Cultivar Type, Cultivation Year, and Site on the Lignans and Related Phenolic Profiles, and the Health-Promoting Antioxidant Potential of Flax (Linum usitatissimum L.) Seeds. Molecules 2018, $23,2636$. [CrossRef]

38. Hano, C.; Tungmunnithum, D. Plant Polyphenols, More than Just Simple Natural Antioxidants: Oxidative Stress, Aging and Age-Related Diseases. Medicines 2020, 7, 26. [CrossRef] [PubMed]

39. Abbasi, B.H.; Siddiquah, A.; Tungmunnithum, D.; Bose, S.; Younas, M.; Garros, L.; Drouet, S.; Giglioli-Guivarc'h, N.; Hano, C. Isodon rugosus (Wall. ex Benth.) Codd In Vitro Cultures: Establishment, Phytochemical Characterization and In Vitro Antioxidant and Anti-Aging Activities. Int. J. Mol. Sci. 2019, 20, 452. [CrossRef] 
40. Nazir, M.; Tungmunnithum, D.; Bose, S.; Drouet, S.; Garros, L.; Giglioli-Guivarc'h, N.; Abbasi, B.H.; Hano, C. Differential Production of Phenylpropanoid Metabolites in Callus Cultures of Ocimum basilicum L. with Distinct in Vitro Antioxidant Activities and in Vivo Protective Effects against UV stress. J. Agric. Food Chem. 2019, 67, 1847-1859. [CrossRef]

41. Rice-Evans, C.A.; Miller, N.J.; Paganga, G.; Catherine, A.R.-E.; Nicholas, J.M.; George, P. Structure-antioxidant activity relationships of flavonoids and phenolic acids. Free Radic. Biol. Med. 1996, 20, 933-956. [CrossRef]

42. Vo, Q.V.; Nam, P.-C.; Thong, N.M.; Trung, N.T.; Phan, C.-T.D.; Mechler, A. Antioxidant Motifs in Flavonoids: O-H versus C-H Bond Dissociation. ACS Omega 2019, 4, 8935-8942.

43. Prior, R.L.; Wu, X.; Schaich, K. Standardized Methods for the Determination of Antioxidant Capacity and Phenolics in Foods and Dietary Supplements. J. Agric. Food Chem. 2005, 53, 4290-4302. [CrossRef] [PubMed]

44. Thiers, B.; Thiers, B.H.; Cokic, B.B.B. Index Herbariorum: A Global Directory of Public Herbaria and Associated Staff; New York Botanical Garden's Virtual Herbarium: New York, NY, USA, 2009.

45. World Health Organization. Quality Control Methods for Medicinal Plant Materials; World Health Organization: Geneva, Switzerland, 1998; ISBN 9241545100.

46. Tungmunnithum, D.; Elamrani, A.; Abid, M.; Drouet, S.; Kiani, R.; Garros, L.; Kabra, A.; Addi, M.; Hano, C. A Quick, Green and Simple Ultrasound-Assisted Extraction for the Valorization of Antioxidant Phenolic Acids from Moroccan Almond Cold-Pressed Oil Residues. Appl. Sci. 2020, 10, 3313. [CrossRef]

47. Wrolstad, R.E. Color and pigment analyses in fruit products. Agric. Exp. Stn. 1993, 5, 4-20.

48. Hammer, Ø.; Harper, D.A.; Ryan, P.D. PAST: Paleontological statistics software package for education and data analysis. Palaeontol. Electron. 2001, 4, 9. 